\title{
Rehabilitation in Autism. Pilot Project on the Health Centre-Based Primary Care Model within the National Health Plan Implementation Projects
}

\author{
Stefano Marini' ${ }^{1}$, Tatiana D’Ambrogio², Marco Esposito³, Maria Rita Sergi ${ }^{4}$, Germana Sorge ${ }^{1}$ \\ ${ }^{1}$ Il Cireneo Foundation for Autism, Vasto, Italy \\ ${ }^{2}$ National Health System, Child Neuro-Psychiatry Territorial Service, L'Aquila-Avezzano-Sulmona, Italy \\ ${ }^{3}$ Fondazione Istituto Ospedaliero Sospiro, Cremona, Italy \\ ${ }^{4}$ Centro Terapie Educative, C.T.E. Srl, Rignano Sull'Arno, Firenze, Italy \\ Email: info@fondazioneilcireneo.it
}

How to cite this paper: Marini, S., D'Ambrogio, T., Esposito, M., Sergi, M.R. and Sorge, G. (2018) Rehabilitation in Autism. Pilot Project on the Health Centre-Based Primary Care Model within the National Health Plan Implementation Projects. Open Journal of Psychiatry, 8, 182-197.

https://doi.org/10.4236/ojpsych.2018.82017

Received: March 20, 2018

Accepted: April 25, 2018

Published: April 28, 2018

Copyright $\odot 2018$ by authors and Scientific Research Publishing Inc. This work is licensed under the Creative Commons Attribution International License (CC BY 4.0).

http://creativecommons.org/licenses/by/4.0/

cC) (i) Open Access

\begin{abstract}
Background: In Italy, there is a lack of reliable data on the epidemiology of Autism Spectrum Disorder (ASD) on a national scale. The exact etiopathogenesis of ASDs is still largely unknown, with autism representing the final common pathway of different pathological conditions. Aim of the Study: Assessment of the effects produced by the individualised, intensive and holistic rehabilitation programme used by the Il Cireneo Foundation on the daily living skills of people diagnosed with ASD. Materials and Methods: Out of the eighty-seven ( $\mathrm{n}=$ 87) enrolees, seventy-nine $(n=79)$, of whom 19 were females $(24.1 \%)$ and 60 were males $(75.9 \%)$, with a mean age of 13.41 years $(\mathrm{SD}=6.93$ years; range $=2$ 33 years) terminated the three-year study. The enrolees were evaluated two times: at the beginning of the rehabilitation programme and at the end of the three-year goal-oriented project. Results: Statistically significant results between T0 and T1 were recorded for CARS ( $\mathrm{t}-4.221 ; \mathrm{p}<0.05)$ and for the domains of Communication ( $\mathrm{t}-2.750 ; \mathrm{p}<0.05)$, Daily Living Skills $(\mathrm{t}-6.526 ; \mathrm{p}<0.05)$ and Motor Skills ( $\mathrm{t}-3.524 ; \mathrm{p}<0.05)$ of the VABS. Conclusions: People diagnosed with autism can be helped to become more autonomous and independent in carrying out activities of daily living thanks to an intensive psycho-educational and cognitive-behavioural rehabilitation programme, of which the Il Cireneo Foundation is the only expression in the Abruzzo region.
\end{abstract}

\section{Keywords}

Autism Spectrum Disorder, Rehabilitation, TEACCH 


\section{Background}

\subsection{The Health Centre-Based Primary Care Model within the National Health Plan Implementation Projects}

The Fondazione II Cireneo Onlus per P Autismo was set up in 2003 by the parents of children affected by autism spectrum disorder, also known as Founders, who, after working as an association, developed the idea, and especially the need, to become active players in the construction of a social and health care network around their children, something which was completely missing in the Abruzzo region. The deficiencies in terms of legislation, regulations and policies on autism were reducing the existence of their children to institutional nothingness, based on the wrong belief that people affected by this "disorder" are irrecoverable, hence, the total absence of pathways of and rights to health care, rehabilitation, and an accurate diagnosis.

This further motivated the Foundation which directed its efforts towards several initiatives and projects, mostly funded by public and private institutions and carried out with the support of volunteers, fixed-term workers and freelance professionals - that is all the tools normally available to the non-profit sector and to those who strive to bridge institutional gaps-thus creating windows of opportunity for children and adolescents affected by autism spectrum disorders.

Amongst the numerous demands brought forward by the Il Cireneo Foundation, the pilot project on the health centre-based primary care model, funded within the implementation framework of the National Health Plan and co-financed by the Abruzzo region, was approved. The project, titled Progetto regionale sperimentale per la riabilitazione ed il trattamento dell autismo e del disturbo generalizzato dello sviluppo nell ambito dell assistenza prevista nella casa della salute (Regional pilot project for the rehabilitation and treatment of autism and pervasive developmental disorders within the health centre-based primary care model), lasted three years, from 2010 to 2013.

In this case, having recourse to a pilot project was necessary, just as it was in the case of 9 other initiatives funded by the national plan, because they are not included in the formally identified health care activities and, therefore, are not covered by the National and Regional Health Service financing.

Pilot projects are indeed funded with the specific goal of generating new types and methods of intervention. The regional and national governing bodies, based on the results achieved and the efficacy of the experimentation, either stabilize the said methods through the legislative processes necessary for the inclusion within the services covered by the Health System, and hence in the essential levels of care (LEA, Livelli essenziali di assistenza), or declare them as ineffective.

The institutions involved in the project were:

- Abruzzo Region;

- Regional Reference Centre for Autism (CRRA, Centro di Riferimento Regionale per l'Autismo);

- Local Health Authorities; 
- Non-profit organisations and foundations;

- Local bodies (and mountain communities);

- Public institutions (schools).

Each one of the institutions involved had specific tasks and objectives that required the involvement of different stakeholders and tools, such as: parents of people diagnosed with autism spectrum disorder, volunteers, casual workers, consultants, professionals, project workers, work grants and scholarships to which local health authorities, the Regional Reference Centre for Autism (CRRA) and the Il Cireneo Foundation had recourse.

The Il Cireneo Foundation, thanks to the support of several consultants and collaborators in different parts of the region, was able to develop a 'rehabilitation project' building on the assessment of patients of different age groups and levels of functioning who were evaluated, before entering the project, by professionals from different local health authorities that were given tasks and responsibilities concerning the economic, healthcare and reporting aspects of the activities carried out and of their efficacy/outcome.

More specifically, the CRRA, from the province of L'Aquila, was in charge of:

- Drawing up a plan of local interventions taking into account the needs represented by each local health authority, based on which the Region would decide on the measures to be taken and the funds to be allocated;

- Gathering documents related to the treatments performed;

- Assessing whether the interventions matched the project purposes and the health care demand;

- Collecting epidemiological data on the incidence and severity of the pathological conditions under consideration; the said data would then be transmitted to the Abruzzo region.

The reference teams, to which the Il Cireneo Foundation delegated healthcare-related tasks, took into consideration the National Guidelines for Autism published in 2005 and 2011, as well as the scientific research and literature that in the past 20 years have given a significant contribution to the understanding of the disorder, despite its unknown etiopathogenesis. They also relied upon the expertise of several national and international professionals, recognised by the Scientific Community. They acknowledged the lack of a proper 'cure', if by cure we mean complete recovery, but they also drew on the tools and methods with proven efficacy adopted at international level, assessing the results of all the projects carried out by the collaborators who were responsible for the implementation of the different social and healthcare processes, both in structured facilities (centres provided by the Foundation) and in other settings (school, home, various stays, etc.). Therefore, thanks to different competencies and to the necessary intellectual resources, they were able to test the best solutions for the development of a rehabilitation project.

The outcome indicators of the pilot project convinced the health planning bodies, completely lacking in responses and resources, to produce the first 
document on regional healthcare needs in 2012 and the first juristic act, with a budget allocated to autism, at the end of 2013.

The current programming documents, dated 2017, have finally established the organisational, structural and staffing regulations thanks to the inclusion of the treatment pathway of people affected by autism in the 2017 essential levels of care (LEA) and to the transposition of the 2015 National Autism Act.

There are still many obstacles to overcome, among which the delivery in the whole region of a treatment pathway and of the facilities necessary for taking care of patients throughout, from early diagnosis to adulthood.

If, on the one hand, institutions should be given credit for believing in and answering the demands brought forward by the Il Cireneo Foundation for the testing of a new treatment model, on the other, the Foundation itself and all those who participated in the pilot project and their parents, are equally praiseworthy because they were the first to believe in autistic people, overcoming the stigma that comes with the diagnosis and the concept of resignation. Special thanks go to all those who funded the construction of facilities, materials and equipment now present in the various centres of the Il Cireneo Foundation for Autism (http://www.fondazioneilcireneo.it/).

\subsection{A Brief History of Autism}

Leo Kanner (1943) in Baltimore [1] and Hans Asperger in Vienna (1944) [2] were the first scholars to describe, without being aware of each other's papers, the main features of autism, although the children described by Asperger had good language and cognitive skills, whereas those described by Kanner presented more differences in IQ and language skills. Initially (1980), since Asperger's papers were in German, only the autism described by Kanner was introduced in the Diagnostic and Statistical Manual of Mental Disorders-Third edition [3], and only in 1992 was Asperger syndrome introduced in the International Classification of Diseases- $10^{\text {th }}$ Revision of the World Health Organization [4] and in 1994 in DSM-IV [5]. In 1976, Wing [6] described the core triad of impairments in autism spectrum disorders including difficulties in communication, social interaction and social imagination (along with repetitive patterns of behaviour). In 2013, in DSM-5 [7], the triad of impairments was reduced to two main dimensions. On the one hand, social interaction and communication difficulties were incorporated, and on the other, the domain of social imagination impairment was eliminated (since autistic people are often extremely imaginative when it comes to art and especially drawing) in favour of repetitive patterns of behaviour which also include limited interests and difficulties in adjusting behaviour to social contexts.

\subsection{Epidemiology}

In Italy there is a lack of reliable data on the epidemiology of Autism Spectrum Disorder (ASD) at national level and the data available refers to the incidence and prevalence in the various regions. In Great Britain, the prevalence of ASDs 
in childhood is approximately $1 \%$ of the population [8], whereas in adulthood the prevalence increases to $1.1 \%$ [9]. In the United States, a recent research pointed out a prevalence of $2.41 \%$ [10]. Looking at Rutter's epidemiological study of 1978 [11], where the prevalence of autism was approximately 4 per 10,000, it is quite easy to understand that autism nowadays is much more frequent as compared to 30 years ago. This is due both to the fact that before 1994 the Asperger Syndrome diagnosis had not yet been included in DSM-IV, and to the lack of adequate services for the diagnosis of autism spectrum disorder. Nevertheless, many adults do not receive a formal diagnosis of this disorder [12].

\subsection{Aetiopathogenesis}

The aetiopathogenesis of ASDs is still largely unknown, with autism representing the final common pathway of different pathological conditions [13]. In the past, the scientific literature proposed three main research areas on this topic:

1) Interpretive models. Interpretive hypotheses can be classified into the following models: social-affective theory, theory of mind, central coherence and executive function.

2) Neurobiological bases. Abnormal brain structures, identified through CT or MRI scans, have been represented by cerebellum [14], frontal lobe, amygdala and hippocampus [15]. Alterations of brain neurotransmitters have also been found [16] [17].

3) Aetiological factors. Although the "autism gene" does not exist, several studies suggest a genetic predisposition or susceptibility [18] [19] [20] (for an exhaustive review of the literature see [17]). In the recent past, a possible correlation in time with vaccines has been called into question [21], although no data has been found to support this hypothesis [22].

\subsection{Physical Health and Psychiatric Comorbidity}

Little data is available on the physical health of adults with ASD, whereas in the case of children there is a larger amount of information. Lack of sleep, gastrointestinal disorders and epilepsy are the most common problems. Children often have trouble falling asleep and having a good night's rest, with frequent awakenings [23] [24], whereas adults report subjective insomnia [25] [26], a longer time falling asleep and night awakenings [27]. In children affected by ASD the risk of developing gastrointestinal disorders, constipation and diarrhoea is tripled as compared to non-autistic children, and the risk of abdominal pain is twice as high [28]. Selective heating often results in inadequate nutrition which in turn leads to altered bowel habits and constipation [29] [30]. Data in the literature shows that epilepsy is more frequent in patients affected by ASD [31]. In the literature there is also evidence showing that autistic adults present with comorbid mental health conditions such as mood and anxiety disorders [32] [33], ADHD [34] and obsessive-compulsive disorder [35]. 


\subsection{Pharmacological Interventions}

Over the years, several and diversified treatments have been proposed to improve the symptoms of ASD, such as pharmacological and non-pharmacological interventions. The current scientific literature on pharmacological interventions in autism is lacking both in placebo-controlled studies and observational studies, thus preventing the collection of objective efficacy data. Furthermore, due to the lack of long-term studies, the information on the safety and tolerability of the drugs used is not yet exhaustive, although recently longitudinal studies have been published on this matter [36] [37].

Nonetheless, the medications most investigated through placebo-controlled clinical trials in ASDs are antipsychotics such as risperidone [38] [39], aripiprazole [40] [41] [42] and olanzapine [43], whereas as for other antipsychotics, such as quetiapine and haloperidol, the literature only includes observational studies or considers their use as add-on therapies [44] [45]. Risperidone proved to be very effective for the improvement of behavioural symptoms (irritability, social withdrawal, hyperactivity and stereotyped behaviour). Two placebo-controlled trials showed the efficacy of aripiprazole for irritability, agitation and self-injury. However, there are no placebo-controlled studies on adults with autism.

\subsection{Non-Pharmacological Interventions}

As far as non-pharmacological interventions are concerned, scientific evidence shows interesting results almost exclusively in relation to children and adolescents. Parent-training programmes are effective for the improvement of social communication and interaction problems in children and adolescents diagnosed with autism spectrum disorder [46]. The Treatment and Education of Autistic and Related Communication Handicapped Children (TEACCH) educational programme [47], produced significant results in the domains of fine and gross motor skills, cognitive performance, social functioning and communication when compared with standard interventions [48]. Amongst intensive behavioural interventions, the Applied Behaviour Analysis (ABA) [49] is the most studied as well as the most effective for the improvement of intellectual abilities, language skills and adaptive behaviour in children with ASD [50] [51]. The cognitive behavioural therapy has proven to be effective for the treatment of anxiety and anger-related symptoms in Asperger syndrome and high-functioning autism [52] [53]. As for communication-centred interventions, such as Augmentative and Alternative Communication (AAC) and Picture Exchange Communication System (PECS), the results seem modest [54] [55].

\section{Aim of the Study}

The purpose of this project was to assess the effects produced by the individualised, intensive and holistic rehabilitation programme used by the Il Cireneo Foundation for Autism on the daily living skills (activities of daily living, communication, socialisation and motor skills) of people diagnosed with autism 
spectrum disorder.

\section{Materials and Methods}

\subsection{People Enrolled in the Study}

A total of eighty-seven $(n=87)$ people diagnosed with ASD with DSM-IV criteria [5] were enrolled in this study sent by the competent multidimensional evaluation unit ("Unità di Valutazione Multidimensionale", UVM). One enrolee was transferred to another facility outside the Foundation and seven enrolees were discharged from the semi-residential care programme before the end of the goal-oriented project because the competent multidimensional evaluation unit decided, after a careful medical assessment, to suspend the rehabilitation treatment due to a significant improvement of the symptoms of autism, considering the rehabilitation no longer necessary in view of the excellent communication and socialisation skills developed by the enrolees. For these reasons, the final number of people on which the statistical analyses were carried out was seventy-nine $(\mathrm{n}=79)$, of whom 19 were females $(24.1 \%)$ and 60 were males (75.9\%), with a mean age of 13.41 years ( $\mathrm{SD}=6.93$ years; range $=2-33$ years). The project lasted three years, from 2010 to 2013, and was conducted at the rehabilitation facilities of the Il Cireneo Foundation.

\subsection{Study Design}

At the time of admission at the rehabilitation centre (time T0), the enrolees were evaluated using the following scales:

- Childhood Autism Rating Scale (CARS) [56] to confirm the diagnosis made by the multidimensional evaluation unit (UVM) and to stress the severity of the ASD core symptoms, with the total score.

- Vineland Adaptive Behaviour Scale (VABS) [57] to assess the efficacy of the rehabilitation treatment.

Upon admission at the different rehabilitation facilities and every six months, the enrolees were subjected to functional assessment in order to better tailor the rehabilitation programme through the following scales based on the enrolee's age:

- Psychoeducational Profile-Revised (PEP-R) [58];

- Adolescent and Adult Psychoeducational Profile (AAPEP) [59];

- TEACCH Transition Assessment Profile (TTAP) [60].

After three years (time T1), that is at the end of the project, the enrolees were evaluated once again using CARS and VABS.

Following regular meetings of the teams involved (doctors, psychologists, teachers and social workers), a rehabilitation plan was develop consisting of an individualised, intensive and holistic programme, based on the TTAP.

\subsection{Statistical Analysis and Ethical Rules}

After a clinical assessment by the multidimensional evaluation unit (UVM), the 
rehabilitation facilities took charge of the enrolees. The parents or legal guardians of each enrolee signed an informed consent form prior to the start of the rehabilitation programme.

The descriptive statistics of the variables under examination were calculated. Each psychological variable examined by calculating the indices of skewness and kurtosis was normally distributed [61]. The paired-samples t-test was used to highlight the differences between the pre and post-treatment phase. The statistical analyses were conducted using the Statistical Package for the Social Science software (SPSS, Inc., 2007), version 13.0 [62].

\section{Results}

Table 1 summarises the descriptive statistics of the sample under examination.

The CARS scores show statistically significant results ( $\mathrm{t}-4.221 ; \mathrm{p}<0.05)$, highlighting a decrease in the test mean values between the start and end of the treatment. The domains of Communication $(\mathrm{t}-2.750 ; \mathrm{p}<0.05)$, Daily Living Skills ( $\mathrm{t}-6.526 ; \mathrm{p}<0.05)$ and Motor Skills $(\mathrm{t}-3.524 ; \mathrm{p}<0.05)$ of the VABS show a statistically significant increase between $\mathrm{T} 0$ and $\mathrm{T} 1$. No statistically significant differences were detected as for Socialisation. In fact, there is only a slight decrease in socialisation (t.443; $p>0.05$ ), but it is not statistically significant (see Table 2).

Table 1. Descriptive statistics and Skewness and Kurtosis indices in T0 and T1.

\begin{tabular}{|c|c|c|c|c|c|c|c|c|}
\hline \multirow{2}{*}{ Tools } & \multicolumn{4}{|c|}{ T0 } & \multicolumn{4}{|c|}{$\mathrm{T} 1$} \\
\hline & $M$ & $S D$ & Skewness & Kurtosis & $M$ & $S D$ & Skewness & Kurtosis \\
\hline CARS & 38.85 & 8.527 & -0.152 & -0.569 & 37.08 & 8.546 & -0.183 & -0.767 \\
\hline Communication & 91.16 & 38.153 & 2.469 & 8.697 & 107.62 & 72.947 & 0.540 & -1.127 \\
\hline Daily Living Skills & 111.16 & 47.844 & 2.149 & 4.636 & 156.52 & 74.143 & 0.488 & -0.539 \\
\hline Socialisation & 91.39 & 25.686 & 1.421 & 5.162 & 89.99 & 44.423 & 0.728 & -0.075 \\
\hline Motor Skills & 105.23 & 16.943 & -0.278 & 0.531 & 112.91 & 25.777 & -1.308 & 2.404 \\
\hline
\end{tabular}

Table 2. Paired-samples t-test.

\begin{tabular}{ccccccc}
\hline & \multicolumn{2}{c}{ Pre-treatment } & \multicolumn{2}{c}{ Post-treatment } & \multirow{2}{*}{ T-Student } & $\mathrm{p}$ \\
\cline { 2 - 5 } & $M$ & $S D$ & $M$ & $S D$ & & \\
\hline CARS & 38.85 & 8.527 & 37.08 & 8.546 & 4.221 & $\mathrm{p}<0.05$ \\
Communication & 91.16 & 38.153 & 107.62 & 72.947 & -2.750 & $\mathrm{p}<0.05$ \\
Daily Living Skills & 111.16 & 47.844 & 156.52 & 74.143 & -6.526 & $\mathrm{p}<0.05$ \\
Socialisation & 91.39 & 25.686 & 89.99 & 44.423 & .443 & $\mathrm{p}>0.05$ \\
Motor Skills & 105.23 & 16.943 & 112.91 & 25.777 & -3.524 & $\mathrm{p}<0.05$ \\
\hline
\end{tabular}

Notes: $M=$ Mean; $S D=$ Standard Deviation. 


\section{Discussion}

As previously stated, the rehabilitation programmes carried out at the rehabilitation facilities of the Il Cireneo Foundation, have been broadly described in the international scientific literature for their efficacy in the rehabilitation of autistic people. However, the efficacy of the said methods has always been tested in children and adolescents, and never in adults with autism.

As shown in the paragraph on results, the statistically significant changes detected after three years of individualised and intensive rehabilitation refer to the CARS and to the VABS domains of communication, daily living skills and motor skills. No statistically significant changes were detected as far as socialisation is concerned.

The improvement in CARS scores does not mean that people diagnosed with autism who undergo a rehabilitation programme no longer present with the core symptoms of ASD, but rather that, thanks to a rehabilitation project such as the one developed by the Il Cireneo Foundation, in some cases it is possible to achieve a more adequate management of the said symptoms. This means that people affected by ASD could be able to develop communication skills suitable to the social context and some daily living skills that could improve their clinical condition.

As suggested by DSM-5, communication impairment is one of the core symptoms of ASD and, as such, difficult to modify. Thanks to a communication-centred intervention, the enrolees showed a statistically significant improvement in the mean scores of the VABS communication domain. From the clinical viewpoint, this resulted in low-functioning enrolees being able to better communicate their requirements and needs, whereas high-functioning enrolees were more loquacious to the extent permitted by the pathological condition and better able to express their moods and emotions.

Motor deficits are not a diagnostic feature of ASDs, although many researchers have shown that children with ASD often present with alterations in motor development and motor skills, both gross [63] [64] and fine [65] [66], in oral motor skills [67] and in visual motor skills [68]. Our sample, following the motor skills rehabilitation programme, showed a statistically significant improvement in the said skills $(t,-3.524 ; p<0.05)$.

The most relevant improvement that can be appreciated from the statistical analysis of our sample refers to daily living skills. In our opinion, this is the area that should be focused upon when dealing with autism rehabilitation, because even though a diagnosis of autism can never be reversed, it can definitely be improved through a better management of daily living skills.

Impaired socialisation is another core symptom of ASD and is one of the most important targets in rehabilitation programmes. The socialisation deficit in children can vary greatly [69] but is often related to different aspects such as eye contact, facial expressions and interaction. Alterations in socialisation can have important consequences for the life of autistic people and their ability to keep a 
job, make friends, have self-esteem, etc. In this study, no statistically significant differences between the pre and post-treatment phase have been detected in this domain; in fact, there even was a decrease in the scores, meaning a decreased socialisation. In authors' opinion this data can be explained by the fact that socialisation impairment is a core symptom of ASD and, as such, is one of the most difficult aspects to modify. In addition, some of the patients enrolled in the study presented with comorbid epilepsy syndromes that hindered or even compromised an improvement in this VABS domain. Moreover, the mean age of the sample is 14 years; could it be possible that the result also depends on this factor? The authors are not aware of any data in this regard in the literature and believe that the research should also investigate this possibility.

The authors want to stress the importance of the said data, since it highlights the actual chances for rehabilitation in autism spectrum disorders, a process that up to a few years ago would have been unthinkable. The sample studied was made up of adult individuals - for whom there is no data in the literature and this research is the first step to this effect-in whom changes are known to be more difficult, due to neurobiological reasons, as compared to children and adolescents. Furthermore, the authors did not exclude from the study the enrolees who had other comorbid conditions, particularly intellectual disability or epilepsy, as doing so could have invalidated, depending on the severity of the said comorbidities, the significance of the results which are, in fact, very interesting.

The authors want to stress that up to a few years ago, when transitioning to adulthood autistic people often "lost" the diagnosis of autism in favour of merely psychiatric diagnoses, above all in order to allow for the prescription of the medications necessary for the management of behavioural crises. To date, with the exception of risperidone and aripiprazole used for the irritability associated with Autism Spectrum Disorders [70] [71], the prescription of the said drugs is still off-label.

Furthermore, since there is no reliable data on the incidence and prevalence of ASDs in Italy, an epidemiological study to this effect is essential to identify the real management needs of this healthcare field, recently included in the essential levels of care.

The limitations of this study are undoubtedly represented by the great variability of the age range of the sample ( 2 - 33 years). Moreover, partly because of the lack of studies to this effect, it was not possible to establish or compare in what percentage the progress achieved in terms of growth and natural alterations by individuals affected by autism, particularly the youngest who could benefit from a very timely intervention, was determined by the rehabilitation programme.

The authors declare that partial data on this study has been presented as a poster at the "20th Euro Congress on Psychiatrists and Psychologists" held in Rome, Italy, on August 7 and 8, 2017 and at the "30th European College of Neuropsychopharmacology" held in Paris, France, from September 2 to 5, 2017 
and published as conference proceedings [72] [73].

\section{Conclusions}

With this pilot study, the authors want to show that, as opposed to the idea that persisted up to a few years ago, the habilitation and rehabilitation of people diagnosed with autism are possible, to the extent allowed for by the pathological condition. It is not the authors' intention to say that with an intensive psycho-educational and cognitive-behavioural rehabilitation programme, people with autism can be completely freed from the core symptoms of the disorder, but that through such intervention, autistic people can be helped to become more autonomous and independent when carrying out activities of daily living. People affected by ASDs, particularly those with high-functioning autism, can be helped to become the leading characters of their own lives.

At present, the Il Cireneo Foundation is the only private facility in the Abruzzo region under contract with the National Health Service to perform the said treatment.

\section{Disclosure}

This manuscript was entirely funded by the authors, and no pharmaceutical companies were informed of or were involved in the study. All authors contributed to this paper with equal efforts. The authors have no potential conflict of interest directly relevant to the contents of the manuscript.

\section{References}

[1] Kanner, L. (1943) Autistic Disturbance of Affective Contact. Nervous Child, 2, 217-250.

[2] Asperger, H. (1944) Die "Autistischen Psychopathen" im Kindesalter. [The "Autistic Psychopaths" in Childhood]. Archiv für Psychiatrie und Nervenkrankheiten, 117, 76-136. https://doi.org/10.1007/BF01837709

[3] American Psychological Association (1980) Diagnostic and Statistical Manual of Mental Disorders (DSM-III). 3rd Edition, APA, Washington, DC.

[4] World Health Organization (1992) The ICD-10 Classification of Mental Behavioural Disorders: Clinical Descriptions and Diagnostic Guidelines. WHO, Geneva, Switzerland.

[5] American Psychological Association (1994) Diagnostic and Statistical Manual of Mental Disorders (DSM-IV). 4th Edition, APA, Washington, DC.

[6] Wing, L. (1976) Early Childhood Autism: Clinical, Educational and Social Aspects. Pergamon Press, Oxford.

[7] American Psychiatric Association (2013) Diagnostic and Statistical Manual of Mental Disorders. 5 Edition, VA, Washington. Arlington.

[8] Baron-Cohen, S., Scott, F.J., Allison, C., Williams, J., Bolton, P., Matthews, F.E. and Brayne, C. (2009) Prevalence of Autism-Spectrum Conditions: UK School-Based Population Study. British Journal of Psychiatry, 194, 500-509. https://doi.org/10.1192/bjp.bp.108.059345

[9] Brugha, T., Cooper, S.A., McManus, S., Purdon, S., Smith, J., Scott, F.J., Spiers, N. 
and Tyree, F. (2012) Estimating the Prevalence of Autism Spectrum Conditions in Adults: Extending the 2007 Adult Psychiatric Morbidity Survey. NHS, The Health and Social Care Information Centre, London.

[10] Xu, G., Strathearn, L., Liu, B. and Bao, W. (2018) Prevalence of Autism Spectrum Disorder among US Children and Adolescents, 2014-2016. JAMA, 319, 81-82. https://doi.org/10.1001/jama.2017.17812

[11] Rutter, M. (1978) Diagnosis and Definition. In: Rutter, M. and Schopler, E., Eds., Autism: A Reappraisal of Concepts and Treatment, Plenum Press, New York, NY, 1-26. https://doi.org/10.1007/978-1-4684-0787-7_1

[12] Brugha, S.T., McManus, S., Bankart, J., Scott, F., Purdon, S., Smith, J., Bebbington, P., Jenkins, R. and Meltzer, H. (2011) Epidemiology of Autism Spectrum Disorders in Adults in the Community in England. Archives of General Psychiatry, 65, 459-465. https://doi.org/10.1001/archgenpsychiatry.2011.38

[13] Baird, G., Cass, H. and Slonims, V. (2003) Diagnosis of Autism. British Medical Journal, 327, 488-493. https://doi.org/10.1136/bmj.327.7413.488

[14] Kemper, T.L. and Bauman, M. (1998) Neuropathology of Infantile Autism. Journal of Neuropathology and Experimental Neurology, 57, 645-652. https://doi.org/10.1097/00005072-199807000-00001

[15] Courchesne, E., Karns, C.M., Davis, H.R., Ziccardi, R., Carper, R.A., Tigue, Z.D., Chisum, H.J., Moses, P., Pierce, K., Lord, C., Lincoln, A.J., Pizzo, S., Schreibman, L., Haas, R.H., Akshoomoff, N.A. and Courchesne, R.Y. (2001) Unusual Brain Growth Patterns in Early Life in Patients with Autistic Disorder. An MRI Study. Neurology, 57, 245-254. https://doi.org/10.1212/WNL.57.2.245

[16] Poustka, F., Benner, A., Lesch, K.P. and Poustka, A. (1997) Serotonin Transporter (5-HTT) Gene Variants Associated with Autism? Human Molecular Genetics, 6, 2233-2338. https://doi.org/10.1093/hmg/6.13.2233

[17] Volkmar, F.R., Lord, C., Bailey, A., Schultz, R.T. and Klin, A. (2004) Autism and Pervasive Developmental Disorders. Journal of Child Psychology and Psychiatry, 45, 135-170. https://doi.org/10.1046/j.0021-9630.2003.00317.x

[18] Bailey, A., et al. (1996) Autism: Towards an Integration of Clinical, Genetic, Neuropsychological, and Neurobiological Perspectives. Journal of Child Psychology and Psychiatry, 37, 89-126. https://doi.org/10.1111/j.1469-7610.1996.tb01381.x

[19] Folstein, S.E. and Rosen-Sheidley, B. (2001) Genetics of Autism: Complex Aetiology for a Heterogeneous Disorder. Nature Review Genetics, 2, 943-955. https://doi.org/10.1038/35103559

[20] Szatmari, P., Jones, M.B., Zwaigenbaum, L. and MacLean, J.E. (1998) Genetics of Autism: Overview and New Directions. Journal of Autism and Developmental Disorders, 28, 351-368. https://doi.org/10.1023/A:1026096203946

[21] Wakefield, A.J., Murch, S.H., Anthony, A., Linnell, J., Casson, D.M., Malik, M., Berelowitz, M., Dhillon, A.P., Thomson, M.A., Harvey, P., Valentine, A., Davies, S.E. and Walker-Smith, J.A. (1998) Ileal-Lymphoid-Nodular Hyperplasia, Non-Specific Colitis, and Pervasive Developmental Disorder in Children. The Lancet, 351, 637-641. https://doi.org/10.1016/S0140-6736(97)11096-0

[22] Parker, S.K., Schwartz, B., Todd, J. and Pickering, L.K. (2004) Thimerosal-Containing Vaccines and Autistic Spectrum Disorder: A Critical Review of Published Original Data. Pediatrics, 114, 793-804.

https://doi.org/10.1542/peds.2004-0434

[23] Cohen, S., Conduit, R., Lockley, S.W., Rajaratnam, S.M. and Cornish, K.M. (2014) 
The Relationship between Sleep and Behavior in Autism Spectrum Disorder (ASD) a Review. Journal of Neurodevelopmental Disorders, 6, 44. https://doi.org/10.1186/1866-1955-6-44

[24] Richdale, A.L. and Schreck, K.A. (2009) Sleep Problems in Autism Spectrum Disorders: Prevalence, Nature, \& Possible Biopsychosocial Aetiologies. Sleep Medicine Reviews, 13, 403-411. https://doi.org/10.1016/j.smrv.2009.02.003

[25] Baker, E.K. and Richdale, A.L. (2015) Sleep Patterns in Adults with a Diagnosis of High-Functioning Autism Spectrum Disorder. Sleep, 38, 1765-1774. https://doi.org/10.5665/sleep. 5160

[26] Tani, P., Lindberg, N., Nieminen-von Wendt, T., von Wendt, L., Virkkala, J., Appelberg, B. and Porkka-Heiskanen, T. (2004) Sleep in Young Adults with Asperger Syndrome. Neuropsychobiology, 50, 147-152. https://doi.org/10.1159/000079106

[27] Limoges, E., Mottron, L., Bolduc, C., Berthiaume, C. and Godbout, R. (2005) Atypical Sleep Architecture and the Autism Phenotype. Brain, 128, 1049-1061. https://doi.org/10.1093/brain/awh425

[28] McElhanon, B.O., McCracken, C., Karpen, S. and Sharp, W.G. (2014) Gastrointestinal Symptoms in Autism Spectrum Disorder: A Meta-Analysis. Pediatrics, 133, 872-883. https://doi.org/10.1542/peds.2013-3995

[29] Sharp, W.G., Berry, R.C., McCracken, C., Nuhu, N.N., Marvel, E., Saulnier, C.A., Klin, A., Jones, W. and Jaquess, D.L. (2013) Feeding Problems and Nutrient Intake in Children with Autism Spectrum Disorders: A Meta-Analysis and Comprehensive Review of the Literature. Journal of Autism and Developmental Disorders, 43, 2159-2173. https://doi.org/10.1007/s10803-013-1771-5

[30] Berry, R.C., Novak, P., Withrow, N., Schmidt, B., Rarback, S., Feucht, S., Criado, K.K. and Sharp, W.G. (2015) Nutrition Management of Gastrointestinal Symptoms in Children with Autism Spectrum Disorder: Guideline from an Expert Panel. Journal of the Academy of Nutrition and Dietetics, 115, 1919-1927. https://doi.org/10.1016/j.jand.2015.05.016

[31] El Achkar, C.M. and Spence, S.J. (2015) Clinical Characteristics of Children and Young Adults with Co-Occurring Autism Spectrum Disorder and Epilepsy. Epilepsy Behavior, 47, 183-190. https://doi.org/10.1016/j.yebeh.2014.12.022

[32] Hofvander, B., Delorme, R., Chaste, P., Nydén, A., Wentz, E., Ståhlberg, O., Herbrecht, E., Stopin, A., Anckarsäter, H., Gillberg, C., Råstam, M. and Leboyer, M. (2009) Psychiatric and Psychosocial Problems in Adults with Normal-Intelligence Autism Spectrum Disorders. BMC Psychiatry, 9, 35. https://doi.org/10.1186/1471-244X-9-35

[33] Lugnegård, T., Hallerbäck, M.U. and Gillberg, C. (2011) Psychiatric Comorbidity in Young Adults with a Clinical Diagnosis of Asperger Syndrome. Research in Developmental Disabilities, 32, 1910-1917. https://doi.org/10.1016/j.ridd.2011.03.025

[34] Johnston, K., Dittner, A., Bramham, J., Murphy, C., Knight, A. and Russell, A. (2013) Attention Deficit Hyperactivity Disorder Symptoms in Adults with Autism Spectrum Disorders. Autism Research, 6, 225-236. https://doi.org/10.1002/aur.1283

[35] Russell, A.J., Mataix-Cols, D., Anson, M. and Murphy, D.G. (2005) Obsessions and Compulsions in Asperger Syndrome and High-Functioning Autism. British Journal of Psychiatry, 186, 525-528. https://doi.org/10.1192/bjp.186.6.525

[36] Aman, M., Rettiganti, M., Nagaraja, H.N., Hollway, J.A., McCracken, J., McDougle, C.J., Tierney, E., Scahill, L., Arnold, L.E., Hellings, J., Posey, D.J., Swiezy, N.B., Ghuman, J., Grados, M., Shah, B. and Vitiello, B. (2015) Tolerability, Safety, and Benefits of Risperidone in Children and Adolescents with Autism: 21-Month Fol- 
low-up after 8-Week Placebo-Controlled Trial. Journal of Child and Adolescent Psychopharmacology, 25, 482-493. https://doi.org/10.1089/cap.2015.0005

[37] Marrus, N., Underwood-Riordan, H., Randall, F., Zhang, Y. and Constantino, J.N. (2014) Lack of Effect of Risperidone on Core Autistic Symptoms: Data from a Longitudinal Study. Journal of Child and Adolescent Psychopharmacology, 24, 513-518. https://doi.org/10.1089/cap.2014.0055

[38] Sharma, A. and Shaw, S.R. (2012) Efficacy of Risperidone in Managing Maladaptive Behaviors for Children with Autistic Spectrum Disorder: A Meta-Analysis. Journal of Pediatric Healthcare, 26, 291-299. https://doi.org/10.1016/j.pedhc.2011.02.008

[39] Fung, L.K., Mahajan, R., Nozzolillo, A., Bernal, P., Krasner, A., Jo, B., Coury, D. Whitaker, A., Veenstra-Vanderweele, J. and Hardan, A.Y. (2016) Pharmacologic Treatment of Severe Irritability and Problem Behaviors in Autism: A Systematic Review and Meta-Analysis. Pediatrics, 137, 124-135.

https://doi.org/10.1542/peds.2015-2851K

[40] Ching, H. and Pringsheim, T. (2012) Aripiprazole for Autism Spectrum Disorders (ASD). Cochrane Database of Systematic Reviews, 16, CD009043. https://doi.org/10.1002/14651858.CD009043.pub2

[41] Marcus, R.N., Owen, R., Kamen, L., Manos, G., McQuade, R.D., Carson, W.H. and Aman, M.G. (2009) A Placebo-Controlled, Fixed-Dose Study of Aripiprazole in Children and Adolescents with Irritability Associated with Autistic Disorder. Journal of American Academy of Child and Adolescent Psychiatry, 48, 1110-1119. https://doi.org/10.1097/CHI.0b013e3181b76658

[42] Owen, R., Sikich, L., Marcus, R.N., Corey-Lisle, P., Manos, G., McQuade, R.D., Carson, W.H. and Findling, R.L. (2009) Aripiprazole in the Treatment of Irritability in Children and Adolescents with Autistic Disorder. Pediatrics, 124, 1533-1540. https://doi.org/10.1542/peds.2008-3782

[43] Hollander, E., Wasserman, S., Swanson, E.N., Chaplin, W., Schapiro, M.L., Zagursky, K. and Novotny, S. (2006) A Double-Blind Placebo-Controlled Pilot Study of Olanzapine in Childhood/Adolescent Pervasive Developmental Disorder. Journal of Child and Adolescent Psychopharmacolology, 16, 541-548. https://doi.org/10.1089/cap.2006.16.541

[44] Leskovec, T.J., Rowles, B.M. and Findling, R.L. (2008) Pharmacological Treatment Options for Autism Spectrum Disorders in Children and Adolescents. Harvard Review of Psychiatry, 16, 97-112. https://doi.org/10.1080/10673220802075852

[45] Stachnik, J.M. and Nunn-Thompson, C. (2007) Use of Atypical Antipsychotics in the Treatment of Autistic Disorder. Annals of Pharmacotherapy, 41, 626-634. https://doi.org/10.1345/aph.1H527

[46] McConachie, H. and Diggle, T. (2007) Parent Implemented Early Intervention for Young Children with Autism Spectrum Disorder: A Systematic Review. Journal of Evaluation in Clinical Practice, 13, 120-129. https://doi.org/10.1111/j.1365-2753.2006.00674.x

[47] Mesibov, G.B., Shea, V., Schopler, E., Adams, L., Burgess, S., Chapman, S.M., Merkler, E., Mosconi, M., Tanner, C. and Van Bourgondien, M.E. (2005) The TEACCH Approach to Autism Spectrum Disorders. Springer, New York.

[48] Panerai, S., Zingale, M., Trubia, G., Finocchiaro, M., Zuccarello, R., Ferri, R. and Elia, M. (2009) Special Education versus Inclusive Education: The Role of the TEACCH Program. Journal of Autism and Developmental Disorders, 39, 874-882. https://doi.org/10.1007/s10803-009-0696-5

[49] Cooper, J.O., Heron, T.E. and Heward, W.L. (2007) Definition and Characteristics 
of Applied Behavior Analysis. 2nd Edition, Pearson, Upper Saddle River.

[50] Hayward, D., Eikeseth, S., Gale, C. and Morgan, S. (2009) Assessing Progress during Treatment for Young Children with Autism Receiving Intensive Behavioural Interventions. Autism, 13, 613-633. https://doi.org/10.1177/1362361309340029

[51] Virués-Ortega, J. (2010) Applied Behavior Analytic Intervention for Autism in Early Childhood: Meta-Analysis, Meta-Regression and Dose-Response Meta-Analysis of Multiple Outcomes. Clinical Psychology Review, 30, 387-399. https://doi.org/10.1016/j.cpr.2010.01.008

[52] Lang, R., Regester, A., Lauderdale, S., Ashbaugh, K. and Haring, A. (2010) Treatment of Anxiety in Autism Spectrum Disorders using Cognitive Behaviour Therapy: A Systematic Review. Developmental Neurorehabilitation, 13, 53-63. https://doi.org/10.3109/17518420903236288

[53] Sofronoff, K., Attwood, T., Hinton, S. and Levin, I. (2007) A Randomized Controlled Trial of a Cognitive Behavioural Intervention for Anger Management in Children Diagnosed with Asperger Syndrome. Journal of Autism and Developmental Disorders, 37, 1203-1214. https://doi.org/10.1007/s10803-006-0262-3

[54] Schlosser, R.W. and Wendt, O. (2008) Effects of Augmentative and Alternative Communication Intervention on Speech Production in Children with Autism: A Systematic Review. American Journal of Speech-Language Pathology, 17, 212-230. https://doi.org/10.1044/1058-0360(2008/021)

[55] Howlin, P., Gordon, R.K., Pasco, G., Wade, A. and Charman, T. (2007) The Effectiveness of Picture Exchange Communication System (PECS) Training for Teachers of Children with Autism: A Pragmatic, Group Randomised Controlled Trial. Jour nal of Child Psychology and Psychiatry, 48, 473-481. https://doi.org/10.1111/j.1469-7610.2006.01707.x

[56] Schopler, E., Reichler, R.J. and Renner, B.R. (1986) The Childhood Autism Rating Scale (CARS). Irvington, New York.

[57] Sparrow, S.S., Balla, D.A. and Cicchetti, D.V. (2003) Adattamento italiano a cura di Balboni G e Pedrabissi L. Edizioni Giunti OS.

[58] Schopler, E., Reichler, R.J., Bashford, A., Lansing, M. and Marcus, L. (1990) Individualized Assessment and Treatment for Autistic and Developmentally Disabled Children (Vol. 1) Psychoeducational Profile-Revised (PEP-R). Pro-Ed, Austin.

[59] Mesibov, G.B., Schopler, E., Schaffer, B. and Landrus, R. (1988) Individualized Assessment and Treatment for Autistic and Developmentally Disabled Children: Vol. 4. Adolescent and Adult Psychoeducational Profile (AAPEP). Pro-Ed, Austin.

[60] Mesibov, G.B., Thomas, J.B., Chapman, S.M. and Schopler, E. (2007) TTAP: TEACCH Transition Assessment Profile. 2nd Edition, Pro-Ed, Austin.

[61] Ercolani, A.P. and Perugini, M. (1997) La misura in psicologia: Introduzione ai test psicologici. LED.

[62] Statistical Package for the Social Science (2007) SPSS for Windows. SPSS Inc., Chicago.

[63] Dyck, M.J., Piek, J.P., Hay, D.A. and Hallmayer, J.F. (2007) The Relationship between Symptoms and Abilities in Autism. Journal of Developmental and Physical Disabilities, 19, 251-261. https://doi.org/10.1007/s10882-007-9055-7

[64] Provost, B., Lopez, B.R. and Heimerl, S. (2007) A Comparison of Motor Delays in Young Children: Autism Spectrum Disorder, Developmental Delay, and Developmental Concerns. Journal of Autism and Developmental Disorders, 37, 321-328. https://doi.org/10.1007/s10803-006-0170-6 
[65] Lopata, C., Hamm, E.M., Volker, M.A., Sowinski, J.E. and Thomeer, M.L. (2007) Motor and Visuomotor Skills of Children with Asperger's Disorder: Preliminary Findings. Perceptual and Motor Skills, 104, 1183-1192. https://doi.org/10.2466/pms.104.4.1183-1192

[66] Berkeley, S.L., Zittel, L.L., Pitney, L.V. and Nichols, S.E. (2001) Locomotor and Object Control Skills of Children Diagnosed with Autism. Adapted Physical Activity Quarterly, 18, 405-416. https://doi.org/10.1123/apaq.18.4.405

[67] Gernsbacher, M.A., Sauer, E.A., Geye, H.M., Schweigert, E.K. and Goldsmith, H.H. (2008) Infant and Toddler Oral- and Manual-Motor Skills Predict Later Speech Fluency in Autism. Journal of Child Psychology and Psychiatry, 49, 43-50. https://doi.org/10.1111/j.1469-7610.2007.01820.x

[68] Kurtz, L.A. (2006) Visual Perception Problems in Children with AD/HD, Autism, and Other Learning Disabilities: A Guide for Parents and Professionals. Jessica Kingsley Publishers, Philadelphia.

[69] Constantino, J.N., Davis, S.A., Todd, R.D., Schindler, M.K., Gross, M.M., Brophy, S.L., Metzger, L.M., Shoushtari, C.S., Splinter, R. and Reich, W. (2003) Validation of a Brief Quantitative Measure of Autistic Traits: Comparison of the Social Responsiveness Scale with the Autism Diagnostic Interview-Revised. Journal of Autism and Developmental Disorders, 33, 427-433. https://doi.org/10.1023/A:1025014929212

[70] https://www.janssenmd.com/pdf/risperdal/risperdal_pi.pdf

[71] https://www.accessdata.fda.gov/drugsatfda_docs/label/2014/021436s038,021713s030 ,021729s022,021866s023lbl.pdf

[72] Marini, S., D’Ambrogio, T., Sergi, M.R., Gambi, F., Di Giannantonio, M. and Sorge, G. (2017) Rehabilitation in Autism Spectrum Disorder: A Three Year Longitudinal Study. Journal of Psychiatry, 20, 69.

[73] Marini, S., D’Ambrogio, T., Sergi, M.R., Gambi, F., Di Giannantonio, M. and Sorge, G. (2017) Rehabilitation in Adolescents with Autism Spectrum Disorder: A Three-Year Longitudinal Study. European Neuropsychopharmacology, 27, S1096-S1097. https://doi.org/10.1016/S0924-977X(17)31905-3 